\title{
A Proposal for the Clinical Use of Flecainide
}

\author{
JEFFREY L. ANDERSON, MD, JAMES R. STEWART, MD, and BARRY J. CREVEY, MD
}

Effective antiarrhythmic therapy requires a carefully considered approach, including an understanding of the arrhythmia, the underlying cardiac disease and the drug's pharmacokinetics. Flecainide is a new antiarrhythmic drug that may soon be released for general use. Flecainide demonstrates unsurpassed efficacy in chronic ventricular arrhythmias in stable patients and may become a first-choice drug because of its ease of administration, efficacy and favorable tolerance. Twice-daily dosing with 100 to $200 \mathrm{mg}$ usually provides effective therapy. Clinical experience suggests flecainide to be indicated in the treatment of uniform and multiform ventricular premature complexes, coupled ventricular premature complexes, and episodes of nonsustained ventricular tachycardia. A lower re- sponse rate is observed in preventing induction of sustained ventricular tachycardia, and these patients should be carefully selected. Flecainide is promising in the treatment of supraventricular tachycardias using atrioventricular nodal or extranodal reentrant pathways, although this use is still investigational in the United States. The drug's use for arrhythmias during acute myocardial infarction requires further study. Flecainide possesses modest negative inotropic potential. Proarrhythmic or other adverse reactions have occurred primarily in settings of high drug level, poor ventricular function or refractory, malignant arrhythmias, suggesting caution in these groups.

(Am J Cardiol 1984;53:112B-119B)
Effective therapy of cardiac arrhythmias requires a carefully considered approach. ${ }^{1}$ The first step in arrhythmia management is an accurate cardiac diagnosis, which includes documentation and identification of the arrhythmia and evaluation of underlying heart disease. Specific initiating factors should be identified. Electrolyte, acid base and other metabolic derangements, neuroendocrine factors or adverse drug interactions should be addressed. Antiarrhythmic goals should be specified in advance and may include elimination of symptoms (palpitation), suppression of ectopic ventricular complexes, elimination of repetitive complexes or prevention of ventricular tachycardia and fibrillation. Drug administration should be based on sound clinical and pharmacologic principles. Disease states may alter drug effects and disposition. Once therapy has begun, careful follow-up should be undertaken, including documentation of antiarrhythmic effects, observation for adverse effects and, when appropriate, drug plasma concentration.

In association with organic heart disease, particularly

From the University of Utah College of Medicine, Division of Cardiology, Salt Lake City, Utah, and University of Michigan School of Medicine, Ann Arbor, Michigan.

Address for reprints: Jeffrey L. Anderson, MD, University of Utah College of Medicine, c/o LDS Hospital, 325 8th Avenue, Salt Lake City, Utah 84143. coronary artery disease, complex ventricular arrhythmias may be associated with an increased risk of mortality, particularly from sudden death due to ventricular fibrillation. ${ }^{2,3}$ Studies documenting the ability of antiarrhythmic therapy to reduce this excessive risk are incomplete. However, a carefully applied approach appears to hold promise. ${ }^{4}$ Therapy for ventricular arrhythmias is indicated in the following settings: (1) primary ventricular fibrillation unprovoked by myocardial infarction; (2) complex ventricular arrhythmias (pairs, runs, R-on-T complexes and high frequency arrhythmia) after myocardial infarction, particularly during the first year; (3) complex arrhythmias in association with ischemia; (4) ventricular tachycardia, particularly in coronary artery disease; (5) syncope ascribed to ventricular tachycardia of any origin; (6) arrhythmias causing significant clinical symptoms (palpitation, dyspnea, fatigue and dizziness).,5

An ideal antiarrhythmic drug should possess a high degree of effectiveness, a low level of toxicity with a wide therapeutic range and prolonged antiarrhythmic action. ${ }^{6}$ The clinical management of ventricular arrhythmias remains problematic, however, because of the frequent failure of standard drugs which may be attributable to inadequate antiarrhythmic activity, intolerable adverse effects or compliance problems. In this regard, flecainide acetate possesses several favorable properties compared with available antiarrhythmic agents: excellent antiarrhythmic potency per milligram, effectiveness against ventricular arrhythmias in a high 
percentage of patients, a low incidence of major adverse effects, and a long half-life, which favors patient compliance and continuous antiarrhythmic action. ${ }^{7}$

We are prescnting a long-term patient experience, reviewing important investigative observations (many detailed in this symposium), and formulating guidelines for the initial clinical application of flecainide.

\section{Application of Clinical Pharmacology}

Only by applying a thorough understanding of a drug's unique pharmacologic characteristics can maximal therapeutic benefit be realized (Table I).

Metabolism in humans ${ }^{8}$ : After oral administration, the absorption of flecainide is nearly complete, and presystemic (first-pass) metabolism is negligible, resulting in systemic bioavailability of more than $90 \%$. Peak plasma drug levels occur at about 3 hours (range 1 to 6). Food does not deter the rate or extent of flecainide absorption. Increases in oral dosage lead to increases in plasma level in a linear fashion.

The mean plasma elimination half-life in patients with ventricular arrhythmias as determined in several studies averages about 20 hours (range 12 to 27 ). ${ }^{7,9,10}$ This result is somewhat longer than the 14-hour mean half-life noted after single oral doses given to healthy persons. ${ }^{11}$ Minimum therapeutic plasma concentrations associated with greater than $90 \%$ suppression of ventricular premature complexes (VPCs) in responding patients range from 200 to $1,000 \mathrm{ng} / \mathrm{ml}$ (mean 500). In patients with advanced cardiac disease, major adverse cardiac effects have usually occurred in association with plasma levels greater than 1,000 to $1,500 \mathrm{ng} / \mathrm{ml}$. Because antiarrhythmic effects are related to parent drug, plasma determinations of flecainide may provide useful clinical information. Elimination of flecainide is primarily renal, consisting of unchanged drug and 2 major urinary metabolites with little or no antiarrhythmic activity. Plasma protein binding is low (about 40\%) and independent of plasma drug levels. Drug interactions of consequence have not been observed. Despite the high percentage of flecainide circulating as free drug, its large volume of distribution (about 10 liters $/ \mathrm{kg}$ ) precludes effective removal of flecainide by hemodialysis.

Urinary excretion in moderate renal failure is only somewhat less than that in healthy subjects; in contrast, urinary elimination may be markedly lower with endstage renal disease. Observation suggests a decrease of about $25 \%$ in the rate of flecainide elimination from plasma in patients with congestive heart failure (New York Heart Association class III or IV). Drug interactions with flecainide appear to be minor. The addition of flecainide in subjects receiving maintenance digoxin results in about a $15 \%$ increase in digoxin concentration, an insignificant change. Concurrent administration of flecainide and propranolol results in plasma increases in flecainide averaging $20 \%$ and propranolol of $30 \%$ in healthy subjects. Therefore, the pharmacokinetic profile of flecainide is favorable in many regards, and major anomalies of clinical significance have not been described.

Electrophysiologic implications: Flecainide
TABLE I Clinical Pharmacology of Oral Flecainide

Bioavailability: $>90 \%$

Minimum effective plasma concentration range: 200 to 1,000

$\mathrm{ng} / \mathrm{ml}$ (mean 500)

Elimination half-life: 20 hours (range 12 to 27 )

Elimination: Renal

Plasma protein binding: $40 \%$

Active metabolites: None of significance

belongs to the membrane-stabilizing (class I) group of antiarrhythmic agents; however, it has its own characteristic electrophysiologic profile. ${ }^{12,13}$ In humans, flecainide depresses conduction in all parts of the heart, with greatest effects on the His-Purkinje system. Effects on refractory periods are less pronounced and primarily limited to the ventricle. ${ }^{13}$ Sinus node recovery times are usually unaffected except in certain patients with sick sinus syndrome, in whom flecainide occasionally may result in pronounced lengthening. ${ }^{14}$ Prolongation of PR and QRS intervals is greater during treatment with flecainide than with standard drugs, $7,15,16$ but effects on the QT interval are small ${ }^{15}$ (Table II). Increases in PR and QRS intervals of about $20 \%$ commonly occur at doses of $400 \mathrm{mg} / \mathrm{day}$, and are usually not a cause for concern. $7,13,15$ Those with initially increased PR and QRS intervals are not disproportionately affected.13 Similar electrocardiographic changes also are noted with encainide. ${ }^{17,18}$ Clinically, an increase in electrocardiographic intervals of more than $50 \%$, substantial increases in corrected QT interval ${ }^{19}$ or the development of new bundle branch block should raise a clinical concerm, particularly in patients with advanced disease. The development of bifascicular block or second-degree or greater heart block is an indication for drug reduction or discontinuation unless a pacemaker is present to sustain rhythm.

Hemodynamic considerations: Flecainide has been well tolerated hemodynamically. Blood pressure is typically unchanged. Small increases have occasionally been noted, and rarely increases in antihypertensive therapy are needed. Heart rate is unchanged, although rarely bradycardia or tachycardia may be seen. Among antiarrhythmic drugs, flecainide appears to have intermediate negative inotropic potential. In stable pa-

\section{TABLE ॥ Cardiovascular Effects of Oral Flecainide}

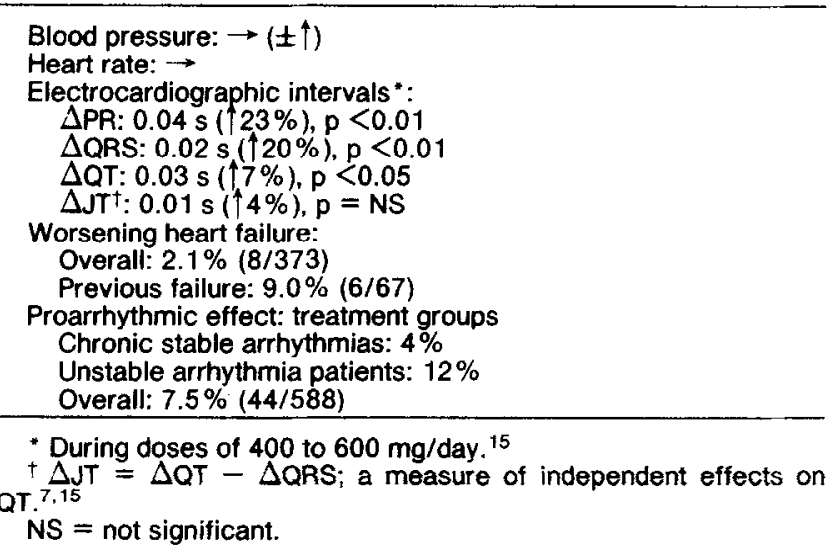


TABLE III Efficacy of Oral Flecainide

\begin{tabular}{|c|c|c|c|c|}
\hline \multirow[b]{2}{*}{ Study (n) } & \multicolumn{4}{|c|}{ Summary of Representative Trials } \\
\hline & $\begin{array}{c}\% \text { Responders } \\
\text { (>80\% VPC Suppression) }\end{array}$ & $\begin{array}{c}\% \text { VPC Suppression } \\
\text { (Mean Frequency Reduction) }\end{array}$ & $\begin{array}{l}\% \text { Suppression } \\
\text { Couplets, Runs }\end{array}$ & $\begin{array}{l}\text { Mean Dose (mg/day) } \\
\text { (Range) }\end{array}$ \\
\hline $\begin{array}{l}\text { Multicenter } \\
\text { dose ranging }(\mathrm{n}=33)^{7,9,10}\end{array}$ & $97(32 / 33)$ & $97 \%$ & $>99 \%$ & $\begin{array}{c}400 \\
(200-600)\end{array}$ \\
\hline $\begin{array}{l}\text { Flecainide-quinidine } \\
\text { comparison }(n=233)^{15} \\
\text { Flecainide, mexiletine, } \\
\text { propafenone } \\
\text { comparison }(n=12)^{22}\end{array}$ & $\begin{array}{l}85 \\
82(9 / 11)\end{array}$ & $\begin{array}{c}95 \%, \text { mean } \\
(99.5 \% \text {, median }) \\
94.2 \%\end{array}$ & $\begin{array}{c}100 \% \text { reduction in } 75 \% \\
80 \% \text { reduction in } 90 \% \\
98.8 \%\end{array}$ & $\begin{array}{c}440 \\
(400 \cdot 600) \\
400\end{array}$ \\
\hline
\end{tabular}

$\mathrm{VPC}=$ ventricular premature complexes.

tients, electrocardiographic ejection fraction does not change during maintenance therapy. ${ }^{7,9,10}$ Twelve patients with compromised left ventricular function were studied by radionuclide ventriculography before and during maintenance therapy: ejection fraction averaged $42 \%$ before and $38 \%$ after therapy; this decrease was not associated with clinical failure. ${ }^{20}$ In a retrospective analysis of 373 patients treated with flecainide, in $4.3 \%$ (16 patients), signs or symptoms developed that might be indicative of heart failure, possibly related to flecainide therapy. In a subgroup with previous heart failure, symptoms developed in $15 \%$ (10 of 67). However, a closer examination of each patient's clinical history indicated that only $2.1 \%$ (8 patients) and $9 \%$ (6 of 67 ), respectively, had evidence of heart failure possibly attributable to flecainide therapy. These figures suggest that flecainide is better tolerated hemodynamically than disopyramide ${ }^{21}$ or propafenone. ${ }^{22}$ In conclusion, flecainide may be used without concern in those with normal or moderately depressed left ventricular function, but caution should be used in those with more advanced dysfunction with preexistent heart failure.

\section{Review of Clinical Experience and Use}

Clinical studies: Flecainide has been administered to approximately 1,000 American patients during clinical investigative studies (Table III). European experience is broader; flecainide has rapidly achieved a position among the most commonly prescribed antiarrhythmic drugs in areas where it is now generally available.

Clinical efficacy of the oral drug was initially demonstrated in the United States in a 3-center dose-finding and short-term efficacy trial.7,9,10 Flecainide therapy resulted in suppression of ventricular premature complexes averaging $97 \%$ in the 33 patients studied. The average dose was $400 \mathrm{mg} /$ day. Repetitive ventricular activity was essentially eliminated.

More recently, the efficacy of flecainide (200 to 300 $\mathrm{mg}$ b.i.d.) has been compared with that of quinidine ( 300 to $400 \mathrm{mg}$ q.i.d.) in a large multicenter trial..$^{15}$ Both drugs were effective in arrhythmia suppression, but the response to flecainide was substantially greater, resulting in $95 \%$ VPC suppression, vs $70 \%$ during quinidine. Seventy-five percent of patients achieved more than $95 \%$ suppression with flecainide, as opposed to $35 \%$ in the parallel group treated with quinidine $(\mathrm{p}<0.001)$.
Couplets were eliminated in $70 \%$ of patients treated with flecainide; quinidine eliminated the couplets in only $41 \%(p<0.001)$. Similarly, ventricular runs were eliminated in $80 \%$ treated with flecainide, vs $55 \%$ with quinidine.

In another clinical trial, the antiarrhythmic efficacy of flecainide was compared with that of mexiletine, a lidocaine congener, and propafenone, another potent type I agent. ${ }^{22}$ Response to flecainide was superior in terms of efficacy and tolerance. Arrhythmia (VPC) reduction averaged $94 \%$ after flecainide $(400 \mathrm{mg} /$ day), $80 \%$ after propafenone $(900 \mathrm{mg} /$ day) and only $53 \%$ after mexiletine $(600 \mathrm{mg} /$ day $)$ in 12 patients with coronary artery disease. Repetitive extrasystoles were reduced by 99,97 and $83 \%$ by the 3 drugs, respectively, in this blinded, crossover study. Side effects led to discontinuation of propafenone and mexiletine in 2 patients each.

Experience has been more limited in patients with inducible ventricular tachycardia by programmed electrical stimulation. ${ }^{13}$ In 15 consecutive patients studied in our laboratory, oral flecainide prevented tachycardia induction in $9(60 \%)$ and improved the response in 2 others, a $73 \%$ overall favorable response. Higher response rates have not been reported for other class I agents. However, response in these patients is evidently less than that in stable patients without ventricular tachycardia and depends on patient selection and stimulation protocol. ${ }^{23,24}$

\section{Long-Term Experience in Treating Complex Arrhythmias}

Antiarrhythmic experience extending over several years is important in assessing clinical safety and efficacy. Such experience with flecainide is still limited and will require further observation. Our own experience with a small group of patients presenting initially with complex ventricular arrhythmias follows.

Ten consecutive patients entered into long-term flecainide therapy on the basis of an initial successful response ( $80 \%$ suppression) (Table IV). ${ }^{7,25}$ At the end of a short-term study (14 days), geometric mean VPC frequency had been reduced by $99.5 \%(p<0.001)$ (Table $\mathrm{V}$ ). The effective drug dose averaged $420 \mathrm{mg} /$ day (range 300 to 600 ), given in divided doses every 12 hours. Median plasma flecainide concentration was $837 \mathrm{ng} / \mathrm{ml}$ (range 357 to 1,615) (Table V). Patients were continued 
TABLE IV Experience with Long-Term Therapy

\begin{tabular}{|c|c|c|c|c|c|c|}
\hline $\mathrm{Pt}$ & $\begin{array}{l}\text { Age }(y r) \\
\& \text { Sex }\end{array}$ & Cardiac Diagnosis & $\begin{array}{l}\text { Arrhythmia } \\
\text { Complexity }\end{array}$ & $\begin{array}{l}\text { No. of } \\
\text { Previous } \\
\text { Drugs }\end{array}$ & $\begin{array}{l}\text { Follow-Up } \\
\text { (mo) }\end{array}$ & Outcome \\
\hline 1 & $62 F$ & $\begin{array}{l}\text { ASD } \\
\text { MVP, MR }\end{array}$ & Couplets & 2 & 28 & $\begin{array}{l}\text { Successful }(\times 28 \text { mo) } \\
\text { late failure (see text) }\end{array}$ \\
\hline 2 & $56 \mathrm{~F}$ & MVP & Runs & 1 & 37 & Successful \\
\hline 3 & $49 F$ & Normal & Couplets & 2 & 36 & Successful \\
\hline 4 & $55 \mathrm{~F}$ & AVD & Multiform & 3 & 35 & Successful \\
\hline 5 & $52 \mathrm{~F}$ & Normal & Runs & 5 & 32 & Successful \\
\hline 6 & $61 \mathrm{M}$ & $\mathrm{CAD}$, old $\mathrm{MI}$ & Runs & 3 & 3 & Failure (exercise VT) \\
\hline 7 & $43 F$ & Normal & Runs & 3 & 10 & Failure (exercise VT) \\
\hline 8 & $69 \mathrm{M}$ & $\mathrm{AS}, \mathrm{CM}$ & Runs & 3 & 21 & $\begin{array}{l}\text { Successful ( } \times 21 \text { mo); } \\
\text { late failure (VT) }\end{array}$ \\
\hline 9 & $70 F$ & Normal & Runs & 5 & 16 & Successful \\
\hline 10 & $67 \mathrm{M}$ & CAD, old $M I$ & Runs & 3 & 9 & Successful \\
\hline
\end{tabular}

* Includes disopyramide (5 patients), lidocaine (1 patient), phenytoin ( 2 patients), procainamide (6 patients), propranolol (6 patients), quinidine ( 8 patients) and tocainide ( 1 patient).

$\mathrm{AS}=$ aortic stenosis; $\mathrm{ASD}=$ atrial septal defect; $\mathrm{AVD}=$ aortic valve disease (biscuspid); $\mathrm{CAD}=$ coronary artery disease; $\mathrm{CM}=$ cardiomyopathy; $\mathrm{MI}=$ myocardial infarction; $\mathrm{MR}=$ mitral regurgitation; $\mathrm{MVP}=$ mitral valve prolapse.

TABLE V Experience with Long-Term Therapy

\begin{tabular}{|c|c|c|c|c|c|c|c|c|}
\hline \multirow[b]{2}{*}{$\mathrm{Pt}$} & \multirow{2}{*}{$\begin{array}{c}\text { Dose } \\
\text { (mg/day) }\end{array}$} & \multicolumn{4}{|c|}{ Average VPCs/Hour } & \multicolumn{3}{|c|}{ Plasma Flecainide (ng/ml) } \\
\hline & & Baseline & 14 Days & 4-8 Mo & $18-36 \mathrm{Mo}$ & 14 Days ${ }^{\ddagger}$ & $6 \mathrm{Mo}^{\S}$ & $30 \mathrm{Mo}^{5}$ \\
\hline $\begin{array}{r}1 \\
2 \\
3 \\
4 \\
5 \\
6 \\
7 \\
8 \\
9 \\
10\end{array}$ & $\begin{array}{l}400 \\
400 \\
600 \\
400 \\
400 \\
500 \\
400 \\
400 \\
300 \\
400\end{array}$ & $\begin{array}{r}125 \\
2,544 \\
636 \\
264 \\
3,468 \\
144 \\
1,854 \\
1,302 \\
1,478 \\
8,100^{\dagger}\end{array}$ & $\begin{array}{r}0 \\
0 \\
6 \\
108 \\
18 \\
0 \\
0 \\
6 \\
0 \\
127\end{array}$ & $\begin{array}{r}1 \\
0 \\
258 \\
0 \\
0 \\
\cdots \\
0 \\
110 \\
129^{*} \\
33\end{array}$ & $\begin{array}{r}16 \\
0 \\
74 \\
2 \\
0 \\
\ldots \\
\ldots \\
2 \\
\ldots \\
\ldots\end{array}$ & $\begin{array}{r}921 \\
544 \\
1,291 \\
357 \\
777 \\
1,615 \\
743 \\
897 \\
\ldots \\
\ldots\end{array}$ & $\begin{array}{r}1,160 \\
892 \\
1,589 \\
1,284 \\
967 \\
1,421 \\
1,047 \\
1,012 \\
845\end{array}$ & $\begin{array}{c}603 \\
1,444 \\
1,476 \\
727 \\
\ldots \\
\ldots \\
\ldots \\
\ldots \\
\ldots\end{array}$ \\
\hline
\end{tabular}

- After attempted dosage reduction.

† Sustained ventricular tachycardia, 136 beats/min.

† Predose (trough).

$\S$ Random.

on the same dose of medication and were followed monthly for 4 months and bimonthly thereafter. History, examination, 12-lead electrocardiography with 1-minute rhythm strip and blood chemistry tests were performed at each visit and 24-hour ambulatory (Holter) electrocardiographic recordings at 4-month intervals.

The follow-up period ranged from 3 months in a patient with early treatment failure to 37 months, with a median of 25 months (Tables IV and V). In the 9 patients successfully treated at 6 months, geometric mean VPC frequency was 8.0 /hour (range 0 to 258 ), representing $99 \%$ suppression with respect to baseline. An additional treatment failure occurred between 6 and 12 months, and 1 each during the second and third treatment years. During successful treatment at 18 to 36 months $(\mathrm{n}=7)$, geometric mean VPC frequency was $6.2 /$ hour (range 0 to 78 ), representing $99.6 \%$ continued VPC suppression.

Treatment failures included ventricular tachycardia in 3 instances and supraventricular arrhythmia in 1. In Patients 6, 7 and 8, spontaneous episodes of more sustained ventricular tachycardia developed despite continued reduction of VPC frequency. In Patients 6 and
7 ventricular tachycardia also occurred during treadmill exercise. Most recent levels in the 4 patients in whom tachyarrhythmias developed were in excess of 1,000 $\mathrm{ng} / \mathrm{ml}$ (mean 1,300).

Side effects were minor. Symptoms occurred early in the course of treatment and did not progress during follow-up. Seven patients complained of intermittent visual blurring and 2 noted a metallic taste. No hematologic or blood biochemistry abnormalities were observed. Electrocardiographic changes, including moderate increases in PR and QRS intervals of 10 to $20 \%$, remained stable.

In summary, flecainide has remained highly effective in reducing VPC frequency in these patients for as long as 37 months (median 25) and is symptomatically well tolerated. ${ }^{25}$ However, spontaneous ventricular tachycardia may still occur in some patients. Disease progression or high plasma levels may have contributed to these failures. Exercise testing was useful in assessing proarrhythmic potential.

Granrud et $\mathrm{al}^{26}$ reported preliminary results of long-term follow-up in 27 patients treated with flecainide. Treatment was stopped in 4 patients, because of sudden death in 1 , heart failure in 1 , right bundle 


\section{TABLE VI Dosage Recommendations for Oral Flecainide} Therapy

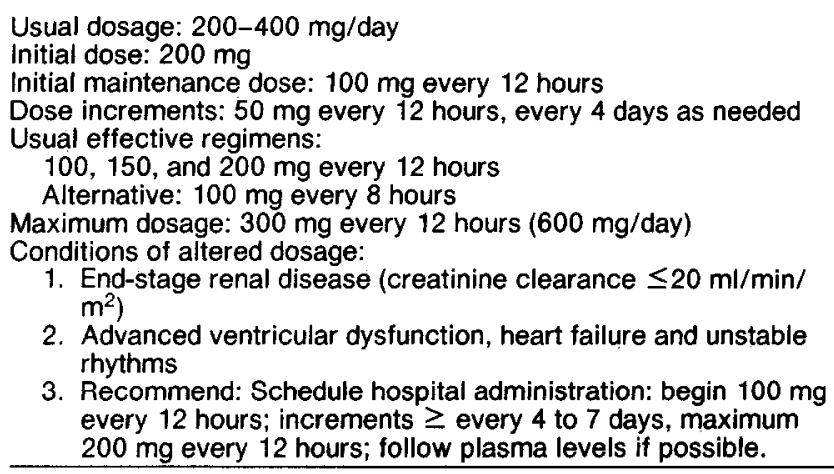

branch block in 1 and inadequate efficacy in 1. Side effects were minor. At 18 to 20 months, mean percent suppression of VPCs and ventricular pairs was $88 \%$ and suppression of ventricular tachycardia $83 \%$ (23 patients). The average dose of flecainide was reduced to a mean of $320 \mathrm{mg} /$ day during chronic therapy, resulting in an average plasma drug level of $577 \mathrm{ng} / \mathrm{ml}$. Flecainide was well tolerated.

\section{Drug Dosage}

Dosing recommendations ('Table VI): Most studies with flecainide have used an average starting dose of 200 $\mathrm{mg}$ every 12 hours, and this dose has been effective and well tolerated in most patients. Because of the long half-life of flecainide, it is likely that even smaller doses (100 to $150 \mathrm{mg}$ every 12 hours) will provide antiarrhythmic efficacy in many patients. Therefore, it is recommended that after a loading dose $(200 \mathrm{mg})$, therapy be initiated at $100 \mathrm{mg}$ every 12 hours. This dose may be increased in increments of $50 \mathrm{mg}$ twice daily every 4 days until efficacy has been achieved or until 400 $\mathrm{mg} /$ day (200 mg twice daily) has been reached. A few

\section{TABLE VII Adverse Reaction Profile}

Neurocirculatory:
Common: Dizziness, blurred vision ( $\sim 30 \%)$
Comment: Usually minor; may decrease with time; usually
responds to dosage reduction if needed
Occasional: Headache and nausea ( 5 to $10 \%$ ); asymptomatic $1^{\circ}$
atrioventricular block
Uncommon: Flushing, chest pain, anxiety, tremor, palpitation,
altered taste, paresthesia, fatigue, asthenia and
hypertension
Proarrhythmic:
Increased VPCs: <5 to 10\% of patients
Comment: More common at subtherapeutic dosage; if so, may
decrease with therapeutic dosage
Facilitation of VT: (1) on ambulatory monitoring (may be independent
of total VPC response), (2) at electrophysiologic induction, and
(3) exercise-induced spontaneous.
Incessant VT or VF (difficult to resuscitate): Very rare.
Comment: Associated with high plasma drug levels $(>1,000$
ng/ml), poor ventricular function (ejection fraction $<30 \%$ ),
history of malignant arrhythmias and \pm concurrent antiar-
rhythmic use; avoid, by careful patient selection and dosage
increments, careful monitoring

VF = ventricular fibrillation; VPC = ventricular premature complexes $\mathrm{VT}=$ ventricular tachycardia. patients have required higher doses, but a dose of 600 $\mathrm{mg}$ /day should not be exceeded.

Dosage increases greater than $400 \mathrm{mg} /$ day should not be made in patients at higher risk for toxicity (heart failure, renal failure with creatinine clearance $\leq 20$ $\mathrm{ml} / \mathrm{min} / \mathrm{m}^{2}$, the very elderly and weight less than $50 \mathrm{~kg}$ ) unless guided by plasma drug concentrations. Again, initial dosage should not exceed $100 \mathrm{mg}$ every 12 hours and increments should be made cautiously, at 4- to 7-day intervals, allowing for steady-state plasma levels to be reached. Studies to determine the effect of hepatic impairment on flecainide elimination have not been completed.

Some patients may be intolerant to or not adequately controlled by a dose given every 12 hours. In these cases, the daily dose may be divided into 8-hour intervals. The long half-life of flecainide suggests the possibility of once-daily dosing in certain patients, but this possibility has not been studied.

\section{Recognizing and Dealing with Adverse Reactions (Table VII)}

Flecainide is well tolerated, although minor adverse effects may be seen. About $30 \%$ of patients receiving an average dose of $400 \mathrm{mg} /$ day or greater have visual disturbance (blurred vision and difficulty in accommodation, particularly on lateral gaze) or dizziness (lightheadedness and unsteadiness). 7,9,10,13,15 These effects most often occur after dosing, during the period of expected drug peak. Complaints of nausea and headache may occur in 5 to $10 \%$ on larger doses. Infrequent effects (incidence of less than $5 \%$ ) include flushing, chest pain, dyspnea, nervousness, palpitation, tremor, paresthesia, fatigue, asthenia and metallic taste. These effects are minor, transient and well tolerated in most patients. In 1 large study, ${ }^{15} 13 \%$ of patients discontinued flecainide because of adverse effects. However, dosages of 400 to $600 \mathrm{mg} /$ day were used, and down-titration was not allowed. Experience in chronic studies indicates that adverse effects may be relieved while efficacy is maintained by downward dose adjustments. ${ }^{26}$ Intolerance should force discontinuation in less than $10 \%$. Flecainide has not caused biochemical or hematologic abnormalities.

Hemodynamic and rhythm effects form the other basis for potential adverse reactions. Worsening of heart failure may occur in approximately $2 \%$ of the patients. First-degree atrioventricular (AV) block is seen frequently, but is usually benign. QRS widening may rarely progress to bundle branch block, usually asymptomatic. Sinus bradycardia, sinus pause, sinus arrest or more advanced AV block is rare, but may occur with preexistent conduction system disease. Proarrhythmic effects are discussed herein.

Precautions: Important drug interactions with flecainide have not been apparent. There has been no experience with co-administration of flecainide and either disopyramide or verapamil. There is little rationale to co-administer disopyramide, particularly in view of the negative inotropic properties of each drug. In appropriate patients, co-administration of verapamil and flecainide may be indicated when the potential benefit 
outweighs the risk (negative inotropy and decreased AV conduction).

Flecainide has not been shown to be carcinogenic in animal studies. ${ }^{27}$ There are no adequate and wèll-controlled studies in pregnancy. Therefore, the drug should be used in pregnancy only if benefit justifies the unknown risk to the fetus. Teratogenic effects were noted in large doses in 1, but not another, strain of rabbit. Effects on human labor and delivery, and excretion in human milk of flecainide have not been studied. Safety and effectiveness of flecainide have not been established in children younger than 18 years of age. In view of flecainide's modest negative inotropic effects, it should be used cautiously in patients with a history of congestive heart failure.

Contraindications: As with other class I antiarrhythmic drugs, flecainide should be considered contraindicated in patients with preexisting second- or third-degree AV block or with bifascicular or trifascicular bundle branch block unless a pacemaker is present that can sustain cardiac rhythm should complete AV block occur. Flecainide is contraindicated in the presence of cardiogenic shock.

Proarrhythmic effects: a clinical caution: A clear understanding of the potential of antiarrhythmic agents to produce proarrhythmic effects is essential to their safe and rational administration ${ }^{28}$; such is also the case for flecainide. ${ }^{29}$ Substantial proarrhythmic effects have been observed with all antiarrhythmic drugs, with an incidence of about 5 to $15 \%$ using ambulatory electrocardiographic recording 28 and about 10 to $30 \%$ during programmed stimulation. ${ }^{30}$ There is also concern with class IC agents. ${ }^{17,18,31}$ The risk of proarrhythmic effects from flecainide appears to be similar: In a survey of 588 patients, $8 \%$ (44 patients) were believed to have such effects. In studies in which only stable patients were recruited, proarrhythmic effects were noted in about $4 \%$, whereas in studies in which unstable patients with advanced disease were recruited, the percentage was $12 \%$ (personal communication, Riker Laboratories). Arrhythmias associated with a long QT syndrome, noted commonly with quinidine, ${ }^{32}$ appear to be rare with flecainide and are associated with toxic doses. ${ }^{19}$ Proarrhythmic effects may take the form of an increased frequency of VPC. If facilitation is mild and occurs in stable patients at subtherapeutic levels, a dosage increase may be considered. Otherwise, alternative therapy should be used. $A n$ increase in repetitive beats (pairs and runs) irrespective of effects on total VPC should be a stronger indication for alternative therapy. Inducibility of ventricular tachycardia at electrophysiologic study in nonresponding patients is unpredictable and may be better, worse or unchanged. ${ }^{13}$ The most serious arrhythmogenic effects have included rare instances of unresuscitable ventricular tachycardia or fibrillation. A recent review among flecainide investigators pointed to a potential role of excessive drug levels $(>1,000 \mathrm{ng} / \mathrm{ml})$ in patients with advanced disease (left ventricular ejection fraction $<30 \%$, previous infarction, history of sustained ventricular tachycardia or concomitant treatment with other class I antiarrhythmic drugs). In these very ill patients with a frequent re-

\section{TABLE VIII Indications for Clinical Use}
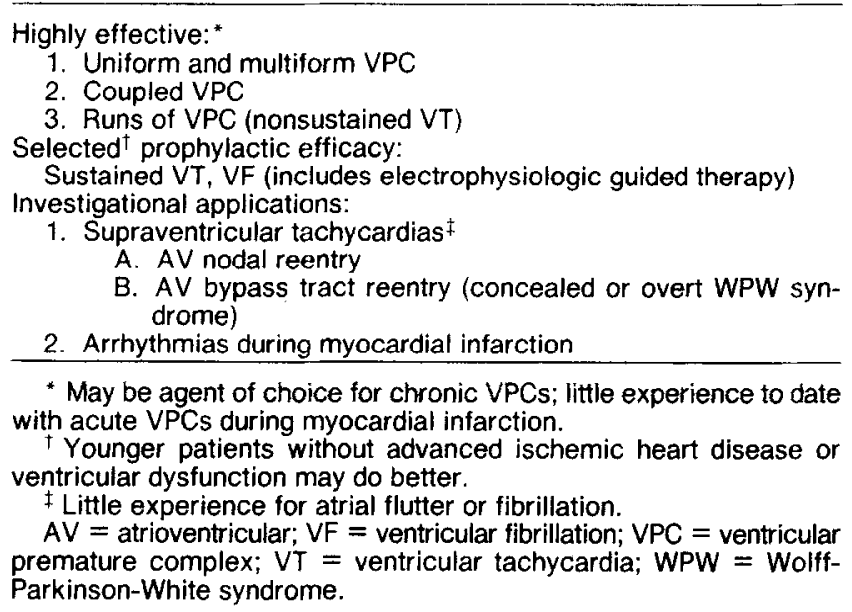

fractory condition, an extremely cautious approach, or alternative therapy, is indicated.

\section{Clinical Proposal for Initial Drug Use}

Flecainide's safety, unsurpassed efficacy and nearideal pharmacokinetics in patients with chronic stable ventricular arrhythmias suggest that it will frequently be the drug of choice when medical treatment is indicated. Studies summarized herein indicate that flecainide will result in greater suppression of ventricular ectopy, including pairs and runs in these patients, than will the standard drugs (quinidine and disopyramide), and the newer lidocaine congeners (i.e., mexiletine and tocainide) soon due for general release in the United States. Convenience of dosing (twice-daily schedule) exceeds that of these other drugs, and adverse effects jeopardizing continued therapy are low.

Proposed indictions for clinical use (Table VIII): Flecainide is proposed for suppression and prevention of uniform and multiform ventricular premature complexes, coupled ventricular premature complexes, and runs of ventricular tachycardia. If the tachycardia is nonsustained, response is followed primarily by ambulatory monitoring; if sustained, therapy may also be directed by programmed electrical stimulation. The response rate of sustained VT is lower and dependent on patient selection; younger patients without coronary disease or, if they have coronary disease, with reasonably well-preserved ventricular function respond most favorably. ${ }^{13}$ The same may be said for other antiarrhythmic drugs. ${ }^{23,24}$ Experience to date is greatest for chronic arrhythmias. Class I antiarrhythmics are usually not effective in treating arrhythmias associated with digitalis intoxication; therefore, flecainide is not recommended for such cases. Although effects of the QT interval are less than those after quinidine, flecainide has not been determined to be useful in the treatment of arrhythmias associated with a long QT interval. Effects of flecainide in patients with supraventricular arrhythmias or acute myocardial infarction have not been adequately studied to provide usage recommendations at this time. In patients with advanced heart disease, including multiple arrhythmia mechanisms, conduction system disease or advanced ventricular 
dysfunction, the increased risks of flecainide's mild negative inotropic effects and potential proarrhythmic effects should be carefully weighed against those of other therapeutic alternatives. $33-36$

Clinical approach: Flecainide, like other antiarrhythmic drugs, should be started during inhospital observation. Most adverse effects of drug occur within a few days of initial administration. In patients with stable arrhythmias without a history of sustained tachycardia, a carefully designed outpatient plan forms an alternative approach. Weekly outpatient visits including ambulatory electrocardiographic recording and symptom assessment may be undertaken until a successful regimen is obtained. Thereafter, the patient may be seen at monthly intervals for 3 months, and 3-month intervals during the first year or as otherwise indicated by the patient's condition. Ambulatory electrocardiographic recordings are obtained until an effective response has been achieved, in the presence of recurrent symptoms or dose adjustment or at about 6-month intervals during at least the first 1 to 2 years.

For patients with a history of, or who have potential for, malignant arrhythmias (sustained ventricular tachycardia, ventricular fibrillation, poor ventricular function and advanced age), inhospital titration (beginning with $100 \mathrm{mg}$ every 12 hours) should be obligatory. Continuous inhospital ambulatory electrocardiographic recording and predischarge exercise testing to a symptomatic end point by treadmill or bicycle ergometry are performed. Patients with a history of sustained ventricular tachycardia are usually tested with programmed electrical stimulation, particularly if spontaneous arrhythmia episodes are infrequent. Blood level monitoring is encouraged when doses of 400 $\mathrm{mg} /$ day or greater are administered and for patients with compromised physiologic findings.

\section{Investigational Use (Table VIII)}

Flecainide is 1 of 4 new antiarrhythmic drugs being tested in the National Institutes of Health-sponsored Cardiac Arrhythmia Pilot Study (CAPS), which began in July 1983. This study in patients with complex arrhythmias in the early period after myocardial infarction will compare the effectiveness of selected antiarrhythmic drugs in suppressing complex ventricular arrhythmias and evaluate their safety. If the results of CAPS are promising, a full-scale trial is proposed to test the hypothesis that elimination of ventricular arrhythmias may reduce the excessive risk of sudden death in this patient group. On the basis of current assessment, flecainide appears to be an excellent candidate drug for such an application.

Another application of great interest includes the use of flecainide for treatment of reentrant supraventricular arrhythmias, including those associated with AV bypass tracts as seen in the Wolff-Parkinson-White syndrome. Preliminary indications suggest that flecainide is an excellent drug in these applications. Hellestrand et a ${ }^{37}$ found flecainide to be effective in treating 12 of 14 cases of $\mathrm{AV}$ bypass tract reentrant tachycardia and 8 of 9 cases of AV nodal reentrant tachycardia evaluated by electrophysiologic study. Flecainide may also be useful in other supraventricular arrhythmias, but further documentation will be required. There is little experience in the prevention or treatment of atrial fibrillation or flutter with flecainide. The therapeutic use of combining flecainide with other antiarrhythmic drugs or nondrug management (pacemakers and internal defibrillators) requires exploration.

Acknowledgment: We acknowledge Terri Johnson, RN, and Joan Lutz, RN, for excellent and ongoing patient care. We thank Marian Curfew and Sandi Olson for typing this manuscript.

\section{References}

1. Anderson JL, Harrison DC, Meffin PJ, Winkle RA. Antiarrhythmic drugs: clinical pharmacology and therapeutic uses. Drugs 1978;15:271-309.

2. Ruberman W, Weinblatt E, Goldberg JD, Frank CW, Shapiro S. Ventricular premature beats and mortality after myocardial infarction. $N$ Engl $\mathrm{J}$ Med 1977-297:750-757.

3. Lown B. Sudden cardiac death: the major challenge confronting contemporary cardiology. Am J Cardiol 1979;43:313-328.

4. Graboys TB, Lown B, Podrid PJ, DeSilva RA. Long-term survival of patients with malignant ventricular arrhythmia treated with antiarrhythmic agents. Am J Cardiol 1982;50:437-443.

5. Anderson $J$. Managing cardiac arrhythmias: an empiric approach. Mod Med Nov. $1981 ; 78-92$

6. Dreifus LS, Ogawa S. Quality of the ideal antiarrhythmic drug. Am J Cardiol 1977:39:466-468.

7. Anderson JL, Stewart JR, Perry BA, Van Hamersveld DD, Johnson TA, Conard GJ, Chang SF, Kvam DC. Pilt B. Oral flecainide acetate for the treatment of ventricular arrhythmias. N Engl J Med 1981;305:473-477.

8. Riker Laboratories. Proposed package insert. Flecainide. February 1983

9. Duft HJ, Roden DM, Maffucci RJ, Vesper BS, Conard GJ, Higgins SB, Oates JA, Smith RF, Woosley RL. Suppression of resistant ventricular armythmias by twice daily dosing with flecainide. Am J Cardiol 1981;48:1133-1140.

10. Hodges M, Haugland JM, Granrud G, Conard GJ, Asinger RW, Mikell FL Krejci J. Suppression of ventricular ectopic depolarization by flecainide acetate, a new antiarrhythmic agent. Circulation 1982;65:879-885.

11. Conard GJ, Carlson GL, Frost JW, Ober RE. Human plasma pharmacokinetics of flecainide acetate (R-818), a new antiarrhythmic, following single netics of flecainide acetate (R-818), a new antiarrhythmic, following sin
oral and intravenous doses (abstr). Clin Pharmacol Ther 1979;25:218.

12. Akeda N, Davis L, Hauswirth $O$, Singh BN. Flecainide: electrophysiologic profile in isolated cardiac muscle of an antiarrhythmic with differential ef fects in ventricular muscle and Purkinje fibers (abstr). Circulation 1982 66:suppl II:H-379.

13. Anderson $\mathrm{JL}$, Lutz JR, Allison $\mathrm{SO}$. Electrophysiologic and antiarrhythmic effects of oral flecainide in patients with inducible ventricular tachycardia. $J$ Am Coll Cardiol 1983;2:105-114.

14. Vik-Mo H, Ohm O-J, Lung-Johansen P. Electrophysiologic effects of fle cainide acetate in patients with sinus nodal dysfunction. Am J Cardiol 1982:50: 1090-1094.

15. Flecainide-Quinidine Research Group. Flecainide versus quinidine for treatment of chronic ventricular arrhythmias: a multicenter clinical trial. Circulation 1983;67:1117-1123.

16. Ross DL, Sze DY, Keefe DL, Swerdlow CD, Echt DS, Griffin JC, Winkie RA, Mason JW. Antiarrhythmic drug combinations in the treatment of ventricular tachycardia. Circulation 1982;66:1205-1210.

17. Anderson JL, Stewart JR, Johnson TA, Lutz JR, Pitt B. Response to encainide of refractory ventricular tachycardia: clinical application of assays for parent drug and metabolites. J Cardiovasc Pharmacol 1982;4:812819 .

18. Mason JW, Peters FA. Antiarrhythmic efficacy of encainide in patients with refractory, recurrent ventricular tachycardia. Circulation 1981;63:670675

19. Lul HG, Lee G, Dietrich P, Low RI, Mason DT. Flecainide-induced QT prolongation and ventricular tachycardia. Am Heart J 1982;103:567569.

20. Lui HK, Lee G, Stobbe D, Harris FJ, Mason DT. Effect of flecainide on left ventricular function (abstr). Clin Res 1983;31:13A.

21. Podrid PJ, Schoeneberget A, Lown B. Congestive heart failure caused by oral disopyramide. N Engl J Med 1980;302:614-617.

22. Klempt HW, Nayebagha A, Fabry E. Antiarrhythmic efficacy of mexiletine, propafenone and flecainide in ventricular premature beats. A comparative study in patients after myocardial infarction. $Z$ Kardiol 1982;71:340349 .

23. Swerdlow CD, Gong G, Echt DS, Winkle RA, Griffin JC, Ross DL, Mason JW. Clinical factors predicting successful electrophysiologlc pharmacologic study in patients with ventricular tachycardia. J Am Coll Cardiol 1983;1: 409-416.

24. Splelman SR, Schwartz JS, McCarthy DM, Horowitz LN, Greenspan AM Sadowski LM, Josephson ME, Waxman HL. Predictors of the success or failure of medical therapy in patients with chronic recurrent sustained ventricular tachycardia: a discriminant analysis. J Am Coll Cardiol 1983. ventricular

25. Van Hamersveld DD, Stewart JR, Johnson TA, Anderson JL. Oral flecainide acetate for long-term treatment of ventricular arrhythmias in man (abstr). Circulation 1981;64:suppl IV:IV-316. 
26. Granrud G, Salerno D, Hodges M, Krejci J, Lebens P, Asinger R. Long-term flecainide is effective and well tolerated (abstr). Circulation 1982;66:suppl tlecainide is
$\|: 11-11-11-69$.

27. Schmid JR, Seebeck BD, Henrie CL, Banitt EH, Kvam DC. Some antiarrhythmic actions of a new compound, R-818, in dogs and mice (abstr). Fed Proc 1975;34:775

28. Velebit V, Podrid P, Lown B, Cohen BH, Graboys TB. Aggravation and provocation of ventricular arrhythmias by antiarrhythmic drugs. Circulation 1982:65:886-893.

29. Nathan A, Hellestrand K, Bexion R, Banim S, Spurrell R, Cannon J. The proarrhythmic effects of the new "antiarrhythmic" drug flecainide acetate (abstr). J Am Coll Cardiol 1983:1:709.

30. Poser R, Lombardi F, Podrid P, Lown B. Aggravation of induced arrhythmias with antiarrhythmic drugs during electrophysiologic testing (abstr). J Am with antiarrhythmic drugs
Coll Cardiol $1983 ; 1: 709$

31. Winkle RA Mason JW, Griffin JC, Ross D. Malignant ventricular tachyarrhythmias associated with the use of encainide. Am Heart $J 1981 ; 102$ :
$857-864$.

32. Reynolds EW, VanderArk CR. Quinidine syncope and the delayed repolarization syndromes. Mod Concepts Cardiovasc Dis 1976;45:117-122.

33. O'Rourke RA, Horwitz LD. Effects of chronic oral quinidine on left ventricular performance. Am Heart J 1981;101:769-773.

34. Giardina EV, Bigger JT. Antiarrhythmic effect of imipramine hydrochloride in patients with ventricular premature complexes without psychologic depression. Am J Cardiol 1982;50:172-179.

35. Nademanee K, Hendrickson JA, Cannon DS, Goldreyer BN, Singh BN. Control of refractory life-threatening ventricular arrhythmias by amiodarone. Am Heart $J$ 1981;101:759-768.

36. Morady F, Scheinman MM, Hess DS, Sung RJ, Shen E, Shapiro W. Electrophysiologic testing in the management of survivors of out-of-hospital trophysiologic lesting in the manlagement or

37. Hellestrand K, Nathan AW, Bexton RS. Effect of flecainide on anomaious pathways and reeentrant junctional tarhyrardia (abstr) Circulation 1982 66:suppl 11:11-69 